\title{
It's not fair to compare transcatheter aortic valve implantation with surgical replacement
}

\author{
Taylan Adademir ${ }^{1}$, Davut Çekmecelioğlu², Deniz Çevirme¹, Mehmet Kalender³, \\ Kamil Boyacıoğlu ${ }^{4}$, Fuat Büyükbayrak ${ }^{5}$, Hızır Mete Alp ${ }^{6}$
}

\footnotetext{
1) Kartal Kosuyolu Yuksek Ihtisas Research and Training Hospital, Cardiovascular Surgery Clinic, M.D., Istanbul, Turkey

2) Kartal Kosuyolu Yuksek Ihtisas Research and Training Hospital, Cardiovascular Surgery Clinic, Assis. Dr., Istanbul, Turkey

3) Kocaeli University of Health Sciences, Derince Education and Research Hospital, Cardiovascular Surgery Clinic, Op. Dr., Kocaeli, Turkey

4) Istanbul Bagcilar Research and Training Hospital, Cardiovascular Surgery Clinic, Op. Dr., Istanbul, Turkey

5) Izmit Konak Hospital, Cardiovascular Surgery Clinic, Assoc. Dr., Izmit, Turkey

${ }^{6}$ Okan University Hospital, Cardiovascular Surgery Clinic, Prof. Dr., Istanbul, Turkey
}

\begin{abstract}
Surgical aortic valve replacement (SAVR) is still class I recommendation for the treatment of patients with symptomatic severe aortic valve stenosis(AS) according to recent guidelines. Although it assumed as one of the most succesful intervention of cardiac surgery; currently the transcatheter technique (transcatheter aortic valve replacement-TAVR) has came into notice as a feasible and effective option to treat high risk or inoperable aortic stenosis patients. New reports have been publishing comparison of these two techniques by numbers increasing with this technology1. On the stage, we would like to discuss about fairness of the comparison mentality in terms of a feature-by-feature style.
\end{abstract}

Key words: Fairness, TAV, SAVR, proscons 
As we all know, gold standart therapy should be surgical replacement for the patients with severe calcific aortic stenosis echocardiographically, either symptomatic or asymptomatic. Conventional SAVR yields excellent results after 1 year in lower-risk patients. Despite that, TAVR is also recommended as class I indication on recent guidelines for patients who inoperabl or have prohibitive high surgical risk with last decision given to Heart Valve Team. ${ }^{2}$

Nonetheless, constitutional complications of TAVR have been surfacing and limiting its use such as embolization of calcified debris and consequent cerebral infarction; complete AV block and need of pacemaker insertion; paravalvular leakage and its effect on longterm survival; coronary ostium closure and even aortic rupture. ${ }^{3,4} \mathrm{Up}$ to $42.5 \%$ complete $\mathrm{AV}$ block, $15 \%$ moderate-to-severe paravalvular leak, and $84 \%$ new cerebral infarction have been reported after TAVR. ${ }^{5}$

Despite higher complication rates in terms of major adverse cardiac and cerebrovascular events (MACCE) among TAVR patients; early studies those compared SAVR and TAVR revealed that TAVR is not inferior to surgical AVR in mortality rates. And even more recent trials claims superior mortality results with TAVR. Randomised and observational evidence adjusted on the baseline patients' characteristics finds a similar risk for 30 days mortality, 1-year mortality, stroke, myocardial infarct (MI) and acute renal injury in TAVR and SAVR. ${ }^{6}$ Also Vernat et al $^{7}$ reported that mitral annular geometry is preserved better by TAVR than by SAVR. They concluded that TAVR might be more physiologic approach for aortic replacement. Kocaaslan et a $1^{8}$ found that the increase in terms of quality of life parameters in the TAVR group was greater than the AVR group at the end of the $3 \mathrm{rd}$ month. Probably, the best attribution to TAVR is being non-invasive method that no need for cardiopulmonary bypass (CBP) during the procedure.

On the other hand, patients with high surgical risk did not have any significant difference for the first year mortality according to two large registries (Partner and GARY $=$ German Registy). But reports showed a twofold increased risk of cerebrovascular accident in the TAVR group. The PARTNER A and B trials showed that survival has been remarkably good, but stroke and perivalvular leakage require further device development. ${ }^{9}$ These findings are far from being gold standard. However, progressing technology will continue to seek new answers to these problems. So, can not surgeons replace the aortic valve surgically which is gold standard with low mortality rates, even for high risk patients?

Fairness always needs feature-by-feature comparison. High technology should be compared with high technology. By using higher technology valves, for example suturless valves, we can speed up the surgery. By reducing cross clamp times, we would decrease operative mortality and morbidity. By using high technology, we can perform aortic valve surgery through minimal approaches via mini (CBP) circuits which would decrease morbidity of the pathology. Mini CBP circuits and cannulas may also decrease mortality rates by reducing inflammatory response which may yield sepsis condition.

Sutureless AVR exploitation self-expanding bioprosthesis is a new and favourable alternative to conventional surgical AVR in elderly and high-risk surgical patients. The advanced benefits of this technology involve improved implantability, shorter aortic crossclamp and cardiopulmonary bypass (CPB) times, promised hemodynamic presentation and easier approach for minimally invasive surgery. ${ }^{10}$

Does faster replacement of the valve make a real significant effect especially in recent days which myocardial protection methods are well developed? There are several publications seeking answers to this question. Ranucci et $\mathrm{al}^{11}$ showed that the aortic cross clamping time was an independent predictor of severe cardiovascular morbidity, with an increased risk of $1.4 \%$ per 1 min increase. Patients with a left ventricular ejection fraction $<$ or $=40 \%$ showed the most relevant clinical benefits induced by reduction in cross clamp time.

Additionly, this technology admits entire removal of the diseased native valve and also consists a appropriate alternative to multiple valve procedures or associated coronary artery bypass grafting. Several European case series have demonstrate excellent early clinical and hemodynamic results. ${ }^{12}$ 
We can observe zero in hospital mortality and significantly lower paravalvular leak in high risk patients whom hospital mortality is $5.3 \%$ for TAVR group by adding only one high technology to surgical arm which is suturless valve. Comparative reports between sutureless valves and TAVR in intermediate and high risk patients have shown lower rate of perioperative complications in terms of MACCE and enhanced survival at 24-month follow-up with sutureless valves. ${ }^{3,13} \mathrm{We}$ can easily assume that the results would be even better if we can add mini CBP techniques into these technology. Consequently, sutureless aortic bioprostheses has been situated as an alternative to conventional surgical AVR or TAVR in elderly and high-risk patients. However, the need of multi-centered, randomized trials can not be ignored.

Cardiovascular surgeons involved in the treatment of valve diseases should be open to the introduction of innovative methods, technologies or hypothesis. Also he/she should not get carried off and should always examine the outcomes in the light of well-conducted short and long term clinical trials. Apperently that we must utilize the science strictly to keep patients' safety. ${ }^{14}$

TAVR is growing as a minimally invasive therapy for patients with severe AS. Today, it is completely acceptable that TAVR is already preferable in an increasing proportion of elderly and high risk patients; nevertheless, this procedure has potential for serious complications. The recent evidence and outcomes has showed that its feasibility and efficacy. They drawn the attention of industry and physicians to this new technology. There is little evidence on the long-term outcomes in spite of short-term efficacy is good. We aware that AVR treats the disease quite constantly and it is still considered the standard treatment for most of patients. The future is expected to be more wealthy as new developments and statistics got from continued trials. They will also provide the background to expand physicians' decision area and their applications. Lastly, Bavaria $^{15}$ et all found that not only were surgeons actively involved in the treatment decision-making process, but also played a significant role in the valve procedure, including deployment and post-procedural care of TAVR patients according the Society of Thoracic Surgerons(STS) survey. That is why cardiac surgeons need to have real and fair statement about TAVR.

Choice of SAVR, TAVR or suturless AVR and indications would be concisely established by fairness with a broader spectrum of patients. 


\section{References}

1. Leon, Martin B., et al. "Transcatheter or surgical aortic-valve replacement in intermediate-risk patients.” N Engl J Med 2016.374 (2016): 1609-1620.

2. Nishimura, Rick A., et al. "2014 AHA/ACC guideline for the management of patients with valvular heart disease." Circulation (2014):

3. Biancari, Fausto, et al. "Immediate outcome after sutureless versus transcatheter aortic valve replacement.” Heart and vessels 31.3 (2016): 427-433.

4. Daneault, Benoit, et al. "Stroke associated with surgical and transcatheter treatment of aortic stenosis: a comprehensive review." Journal of the American College of Cardiology 58.21 (2011): 2143-2150.

5. Sinning, Jan-Malte, et al. "Aortic regurgitation index defines severity of peri-prosthetic regurgitation and predicts outcome in patients after transcatheter aortic valve implantation." Journal of the American College of Cardiology 59.13 (2012): 1134-1141.

6. Nagaraja, Vinayak, et al. "Transcatheter versus surgical aortic valve replacement: a systematic review and meta-analysis of randomised and non-randomised trials." (2014): e000013.)

7. Vergnat, Mathieu, et al. "The effect of surgical and transcatheter aortic valve replacement on mitral annular anatomy." The Annals of thoracic surgery 95.2 (2013): 614-619.

8. Kocaaslan, Cemal, et al. "Comparison of Transcatheter Aortic Valve Implantationversus Surgical Aortic Valve Replacement to Improve Quality of Life in Patients> 70 Years of Age with Severe Aortic Stenosis." Brazilian journal of cardiovascular surgery 31.1 (2016): 1-6.
9. Svensson, Lars G., et al. "A comprehensive review of the PARTNER trial." (2013): S11-S16.

10. Santarpino G, Pfeiffer S, Concistré G, Grossmann I, Hinzmann M, Fischlein T. The Perceval S aortic valve has the potential of shortening surgical time: does it also result in improved outcome? Ann Thorac Surg. 2013;96(1):77-81

11. Ranucci, Marco, et al. "Aortic cross-clamp time, new prostheses, and outcome in aortic valve replacement." The Journal of heart valve disease 21.6 (2012): 732-739.

12. Folliguet TA, Laborde F, Zannis K, Ghorayeb G, Haverich A, Shrestha M. Sutureless Perceval aortic valve replacement: results of two European centers. Ann Thorac Surg. 2012;93(5):1483-8

13. Santarpino G, Pfeiffer S, Jessl J, Dell'Aquila AM, Pollari F, Pauschinger $\mathrm{M}$, et al. Sutureless replacement versus transcatheter valve implantation in aortic valve stenosis: a propensity-matched analysis of 2 strategies in high-risk patients. J Thorac Cardiovasc Surg. 2014;147(2):561-7

14. Saadi, Eduardo Keller. "Percutaneous aortic aortic valve replacement: myth or reality?." Brazilian Journal of Cardiovascular Surgery 23.1 (2008): 93-96.

15. Bavaria, J. E., Prager, R. L., Naunheim, K. S., Allen, M. S., Higgins, R. S., Thourani. STS Executive Committee. (2017). Surgeon Involvement in Transcatheter Aortic Valve Replacement in the United States: A 2016 Society of Thoracic Surgeons Survey. The Annals of Thoracic Surgery.

Received: 30/07/2017

Accepted: 09/11/2017

Published: 15/12/2017

Disclosure and conflicts of interest:

The authors declare no conflict of interest.

Corresponding author:

Davut Çekmecelioğlu

Mail: d.cekmecelioglu@yahoo.com 